\title{
Inhalt - Sommaire - Indice - Cuntegn - Contents
}

Einleitung der Herausgeber . . . . . . . . . . . . . . . . . . . . . . . 7

Introduction des éditeurs . . . . . . . . . . . . . . . . . . . . . . 13

Introduzione dei curatori $\ldots \ldots \ldots \ldots$

Introducziun dals editurs $\ldots \ldots \ldots \ldots \ldots \ldots$

Editors' Introduction . . . . . . . . . . . . . . . . . . . . . . 31

Ausgewählte Bibliografie / Sélection bibliographique / Bibliografia scelta /

Bibliografia tschernida / Selected Bibliography . . . . . . . . . . . . . 37

Bellinzona - Bellinzona (Bellenz) - Bellinzone (Bellence) - Blizuna - Bellinzona

Basi costituzionali per il Cantone di Bellinzona: libertà e indipendenza (1798) . . . . 41

Basi costituzionali per il Cantone di Bellinzona: entrata nella

Repubblica Elvetica (1798) . . . . . . . . . . . . . . . . . . . . . . . 45

$$
\text { Bern-Berne - Berna-Berna-Berne }
$$

Beschluss zur Verfassungsrevision des Kantons Bern und zur Garantie von Menschenund Bürgerrechten (1798) _ . . . . . . . . . . . . . . . . . . .

Décision d'une modification constitutionnelle et garantie des droits de l'homme et du citoyen du Canton de Berne (1798) _ . . . . . . . . . . . . . . . . . 51

Verfassung des Kantons Bern: Notstandsordnung (1798) _ . . . . . . . . . . . . . . 53

Provisorische Verfassung des Kantons Bern (1798) _ . . . . . . . . . . . . . . . 57

Verfassungsentwurf für den Kanton Bern (1798) . . . . . . . . . . . . . . . . . . 63

Verfassungsentwurf für den Kanton Bern (1801) . . . . . . . . . . . . . . . . . . . 109

Verfassung des Kantons Bern (1801) . . . . . . . . . . . . . . . . . . . . . . 115

Verfassungsentwurf für den Kanton Bern (1802) . . . . . . . . . . . . . . . . . 123

Verfassung des Kantons Bern (1803) . . . . . . . . . . . . . . . . . . . . . . . . 135

Constitution du Canton de Berne (1803) . . . . . . . . . . . . . . . . . . . . . . . . 139

Costituzione del Cantone di Berna (1803) . . . . . . . . . . . . . . . . 143

Änderung der Verfassung des Kantons Bern (1813) . . . . . . . . . . . . 146

Vereinigung des Hauptteils des ehemaligen Bistums Basel mit dem

Kanton Bern (1815) . . . . . . . . . . . . . . . . . . . . . . . . . . . 149

Réunion de la partie principale de l'ancien Evêché de Bâle avec le

Canton de Berne (1815) . . . . . . . . . . . . . . . . . . . . . . . . 153

Verfassungsgrundsätze für den Kanton Bern (1815) . . . . . . . . . . . . . . . . 157

Principes constitutionnels du Canton de Berne (1815) . . . . . . . . . . . . . . 163

Erste Änderung der Verfassungsgrundsätze für den Kanton Bern (1815) . . . 168

Première modification des principes constitutionnels du Canton de

Berne (1815) . . . . . . . . . . . . . . . . . . . . . . 172

Zweite Änderung der Verfassungsgrundsätze für den Kanton Bern (1815) . . 176

Deuxième modification des principes constitutionnels du Canton de

Berne (1815) . . . . . . . . . . . . . . . . . . . . . 185 
Dritte Änderung der Verfassungsgrundsätze für den Kanton Bern (1815) . . . . 192

Vierte Änderung der Verfassungsgrundsätze für den Kanton Bern (1815) . . . . 194

Fünfte Änderung der Verfassungsgrundsätze für den Kanton Bern (1816) . . . 197

Sechste Änderung der Verfassungsgrundsätze für den Kanton Bern (1816) . . . 200

Siebte Änderung der Verfassungsgrundsätze für den Kanton Bern (1816) . . . . 202

Achte Änderung der Verfassungsgrundsätze für den Kanton Bern (1816) . . . . 205

Neunte Änderung der Verfassungsgrundsätze für den Kanton Bern (1816) . . . 209

Zehnte Änderung der Verfassungsgrundsätze für den Kanton Bern (1816) . . . 210

Verfassung des Kantons Bern (1816) . . . . . . . . . . . . . . . . . 211

Änderung der Verfassung des Kantons Bern (1831) . . . . . . . . . . . . . . . 216

Modification de la Constitution du Canton de Berne (1831) . . . . . . . . . . . 222

Übergangsverfasssung für den Kanton Bern (1831) . . . . . . . . . . . . . . . . . . 229

Constitution de transition du Canton de Berne (1831) . . . . . . . . . . . . . . . . . 241

Verfassung des Kantons Bern mit Übergangsordnung (1831) . . . . . . . . . . . . . . 253

Constitution du Canton de Berne avec régime de transition (1831) . . . . . . . . . . 273

Verfassungsentwurf für den Kanton Bern (1846) . . . . . . . . . . . . . . . . . . . 291

Projet de Constitution pour le Canton de Berne (1846) . . . . . . . . . . . . . . . . . 303

Verfassung des Kantons Bern (1846) . . . . . . . . . . . . . . . . . . . . . . . . . . . . . . . . . . . . . . . . .

Constitution du Canton de Berne (1846) . . . . . . . . . . . . . . . . . . . . . . 331

Änderung der Verfassung des Kantons Bern (1869) . . . . . . . . . . . . . . . 346

Modification de la Constitution du Canton de Berne (1869) . . . . . . . . . . . 348

\section{Fribourg - Freiburg - Friborgo - Friburg - Fribourg}

Constitution provisoire du Canton de Fribourg (1798) . . . . . . . . . . . . . . . 351

Provisorische Verfassung des Kantons Freiburg (1798) . . . . . . . . . . . . . . 353

Constitution du Canton de Fribourg (1801) . . . . . . . . . . . . . . . . . . 355

Constitution du Canton de Fribourg (1802) . . . . . . . . . . . . . . . . . . . . . . . . . . . . . . . . . . . . . . . . . . .

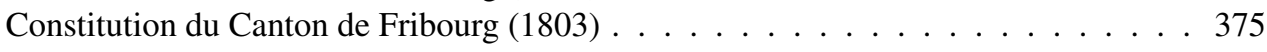

Verfassung des Kantons Freiburg (1803) . . . . . . . . . . . . . . . . . . . . . 379

Costituzione del Cantone di Friburgo (1803) . . . . . . . . . . . . . . . . . 385

Lois constitutionnelles pour le Canton de Fribourg (1803) . . . . . . . . . . . . . . . 389

Konstitutionsgesetze des Kantons Freiburg (1803) . . . . . . . . . . . . . . 405

Modification de la Constitution du Canton de Fribourg (1805) . . . . . . . . . 422

Änderung der Verfassung des Kantons Freiburg (1805) . . . . . . . . . . . . . . . 423

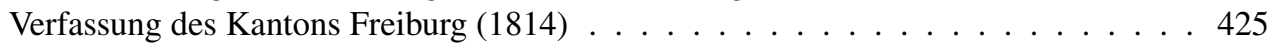

Constitution du Canton de Fribourg (1814) . . . . . . . . . . . . . . . . . . . 433

Änderung der Verfassung des Kantons Freiburg (1830) . . . . . . . . . . . . . 441

Modification de la Constitution du Canton de Fribourg (1830) . . . . . . . . . 443

Constitution du Canton de Fribourg (1831) . . . . . . . . . . . . . . . . . . . . . . . . . . . . . . . . . . . .

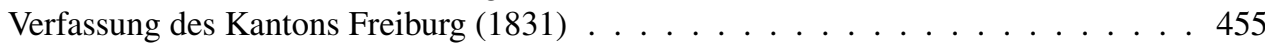

Constitution du Canton de Fribourg (1848) . . . . . . . . . . . . . . . . . . . . 465

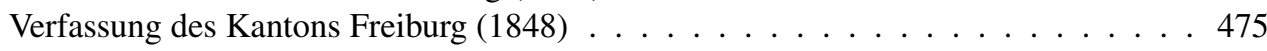

Premier projet de Constitution pour le Canton de Fribourg (1857) . . . . . . . . . . . 485

Deuxième projet de Constitution pour le Canton de Fribourg (1857) . . . . . . . . . 493

Zweiter Verfassungsentwurf für den Kanton Freiburg (1857) . . . . . . . . . . . . 503 
Constitution du Canton de Fribourg (1857) . . . . . . . . . . . . . . . . . . . 513

Verfassung des Kantons Freiburg (1857) . . . . . . . . . . . . . . . . 521

\section{Fricktal (Frickthal)}

Verfassungsentwurf für den Kanton Fricktal (1802) . . . . . . . . . . . . . . . . . . 531

Verfassung des Kantons Fricktal (1802) . . . . . . . . . . . . . . . . . . 537

Constitution du Canton de Fricktal (1802) . . . . . . . . . . . . . . . . . . 543

Änderung der Verfassung des Kantons Fricktal (1802) . . . . . . . . . . . . . . 547

Premier projet d'une nouvelle Constitution pour le Canton de Frickthal (1802) . . . . 549

Deuxième projet d'une nouvelle Constitution pour le Canton de Frickthal (1802) . . 555

Provisorische Verfassung für den Kanton Fricktal (1802) . . . . . . . . . . . . . . . 561

Constitution provisoire pour le Canton de Fricktal (1802) . . . . . . . . . . . . . 565

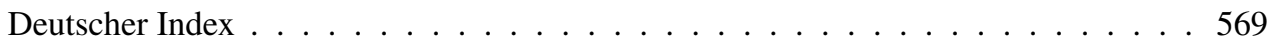

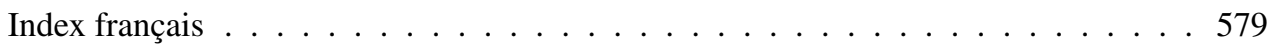

Indice italiano . . . . . . . . . . . . . . . . . . . . . 591

Index rumantsch . . . . . . . . . . . . . . . . . . . . 6603

English Index . . . . . . . . . . . . . . . . . . . 613 
